\title{
Investigation of Nd:YAG pulsed laser dissimilar welding of AISI 4340 and AISI 316L stainless steels on weld geometry and mechanical properties
}

\author{
A.R. Sufizadeh ${ }^{*}$ and S.A.A. Akbari Mousavi \\ School of Metallurgy and Materials Engineering, University College of Engineering, University of Tehran, \\ 11115-4563 Tehran, Iran
}

Received: 18 October 2016 / Accepted: 9 December 2016

\begin{abstract}
In this paper, laser welding of 316L and AISI 4340 steel is studied. Studies are focused on the effects of laser parameters on the depth and width of the welds. The results show that increasing in pulse energy and frequency will increase the weld depth and the weld width. The calculation of effective peak power density related to the welded joints results in optimum operating welding parameters with full penetration and proper dimensions and strengths. The tensile strength values of the full penetrated weldments are greater than the tensile strength values of AISI 316 base metal. The effects of laser parameters on weld grain size and HAZ size were investigated. The results show that the weld grain size and HAZ size increase with pulse energy and frequency.
\end{abstract}

Keywords: Laser parameters / tensile test / grain size / HAZ size / microhardness

\section{Introduction}

The requirement of materials and resource efficiency of the equipment for chemical industry is obtained by improved product design, increasing simultaneously strength and corrosion resistance of the materials used, and by application of novel manufacturing technologies. Dissimilar welding between stainless steel and high strength steel is one of the best approaches to achieve two above properties which have been studied in previous studies [13]. Welding with a pulsed Nd:YAG laser system is characterized by periodic heating of the weld pool by an incident high peak power density pulsed laser beam with consecutive melting and solidification. An experimental investigation, achieved by Ventrella et al. about the influence of the pulse energy on the characteristics of the weld fillet indicates that pulse energy control is of considerable importance to good mechanical properties and also reducing discontinuities in weld joints [4].

In order to welding two dissimilar materials, the selection of proper weld method and variables is very important [5-6]. Laser welding is extensively used due to its small and narrow welding zone and HAZ and less residual stress [7]. Torkamany et al. investigated the effect of laser welding mode on the microstructure and mechanical performance of

\footnotetext{
* e-mail: sufizadeh@ut.ac.ir
}

dissimilar laser spot welds between AISI 1010 and AISI 304. They had studied the effect of the increasing laser mean power on the shape, dimension and structure of the weld fusion zone. Results show that the transition of the laser welding mode from conduction to keyhole welding via increasing the laser mean power significantly affects the fusion zone size in the lower (carbon steel) sheet and in view of that the dilution between two base metals strongly depends on the laser welding mode [8].

Khan et al. had studied the laser beam welding of ferritic AISI 430 and austenitic 304L stainless steels The results have shown that all the weld characteristics lengths and shearing force increase as laser power increases or welding speed decreases. Laser power has the most significant positive effect on all the characteristics lengths except the weld radial penetration [9].

Tadamalle et al. had investigated on influence of laser welding parameters on weld geometry. They found that many parameters such as weld bead geometry, effective pulse energy, energy density, duty cycle, percentage of overlap and pulse off time have been analyzed. Further this work can be extended to study the effect of shielding gas, pulse duration and focal position on duty cycle, weld bead geometry and process efficiencies [10]. The welding speed effects on friction stir welding (FSW) have been studied by Karami et al. and Ugender et al. Their investigation revealed that tunnel defect and flaky surface appeared by carrying out the FSW process in lower rotation speeds or 
Table 1. The laser parameters applied for welding.

\begin{tabular}{rrllll}
\hline Sample number & Pulse energy $(\mathrm{J})$ & Frequency $(\mathrm{Hz})$ & Pulse time $(\mathrm{ms})$ & Average power $(\mathrm{W})$ & Heat input $(\mathrm{J} / \mathrm{mm})$ \\
\hline 1 & 4.00 & 50 & 5 & 200 & 67 \\
2 & 5.50 & 50 & 5 & 275 & 92 \\
3 & 7.50 & 50 & 5 & 375 & 125 \\
4 & 9.00 & 50 & 5 & 450 & 150 \\
5 & 10.50 & 50 & 5 & 575 & 192 \\
6 & 9.50 & 50 & 3 & 475 & 158 \\
7 & 9.50 & 50 & 4 & 475 & 158 \\
8 & 9.50 & 50 & 5 & 475 & 158 \\
9 & 9.50 & 50 & 6 & 475 & 158 \\
10 & 9.50 & 50 & 7 & 475 & 158 \\
11 & 9.50 & 40 & 5 & 380 & 127 \\
12 & 9.50 & 45 & 5 & 428 & 158 \\
13 & 9.50 & 50 & 5 & 475 & 174 \\
14 & 9.50 & 55 & 5 & 522 & 190 \\
15 & 9.50 & 60 & 5 & 570 & \\
\hline
\end{tabular}

Table 2. The chemical composition of the base metals.

\begin{tabular}{lllllllllll}
\hline Material elements & $\mathrm{Si}$ & $\mathrm{P}$ & $\mathrm{S}$ & $\mathrm{Ti}$ & $\mathrm{C}$ & $\mathrm{Mo}$ & $\mathrm{Mn}$ & $\mathrm{Ni}$ & $\mathrm{Cr}$ & $\mathrm{Fe}$ \\
\hline AISI 316L & 0.39 & 0.031 & 0.005 & 0.00 & 0.027 & 2.89 & 1.848 & 10.65 & 16.62 & 68.95 \\
AISI 4340 & 0.35 & 0.010 & 0.001 & - & 0.391 & 0.21 & 0.79 & 1.90 & 0.88 & 74.79 \\
\hline
\end{tabular}

higher welding speeds due to lack of heat input and low flow-ability of the welding material. In contrary, the temperature of stir zone in higher rotation speed or lower welding speed reached to single austenite region owing to significant increment of heat input [11-12].

Malekghaini et al. studied the influence of laser pulse energy, pulse duration, and laser beam travel speed on weld dimensions, microstructure and hardness during overlap laser bead on plate spot welding of low carbon steel. The results showed that full penetration welding low carbon steel sheets can be performed with ND:YAG pulsed Laser with two approaches: high peak power densities and higher travel speeds (higher levels of hardness), or medium peak power densities and medium travel speeds (higher overlapping). Effective peak power density which combines the power density with overlapping factor can be used to enhance the prediction of the weld [13].

Akbarimousavi and Sufizadeh investigated experiment on the dissimilar welding procedure between AISI 630 and AISI 321; the results showed that both the weld depth and width will be increased with the current and the frequency. Also the weld width will decrease with the laser beam diameter, while the weld depth will increase. The maximum weld dimensions can be achieved by the optimum value of the pulse duration which has a bilateral effect [14]. In addition to recent activities, an indentation method had been used by Yonezu et al. evaluating the local mechanical properties of welded stainless steel at a high temperature of $320{ }^{\circ} \mathrm{C}$ [15].
In this paper, AISI 316L austenitic stainless steel was welded by laser to AISI 4340 steel. The possibility of corrosion of weld is approached minimum due to the prevention of chromium carbide in the grain boundaries [16-17].

The AISI 4340 steel is weldable using the fusion welding methods [18]. The investigations on the welding need parameters such as pulse energy, frequency, and pulse time lead to selection of the appropriate heat input, average power and peak power. Therefore, in this paper the sound weld with full penetrate and optimum cross section characteristics are investigated from the mechanical properties point of view.

\section{Materials and methods}

In this study, welding process was performed autogenously using Nd:YAG pulsed laser with the moderate power of $700 \mathrm{~W}$. The laser beam was focused at the interface of the joints. Table 1 lists the various welding tests carried out in this study. In all of these tests, the argon gas with the $99.99 \%$ purity was used with the flow rate of $10 \mathrm{l} / \mathrm{min}$ and the welding speeds were $3 \mathrm{~mm} / \mathrm{s}$. The materials used were the $316 \mathrm{~L}$ and AISI 4340 steels. Their chemical compositions are listed in Table 2. Figure $1 \mathrm{a}$ and $\mathrm{b}$ shows the microstructure of the AISI 4340 and AISI 316L steel. The shapes of the welded samples are shown in Figure 2. The square butt weld joint was used. The thicknesses of the base metals were $0.5 \mathrm{~mm}$. 

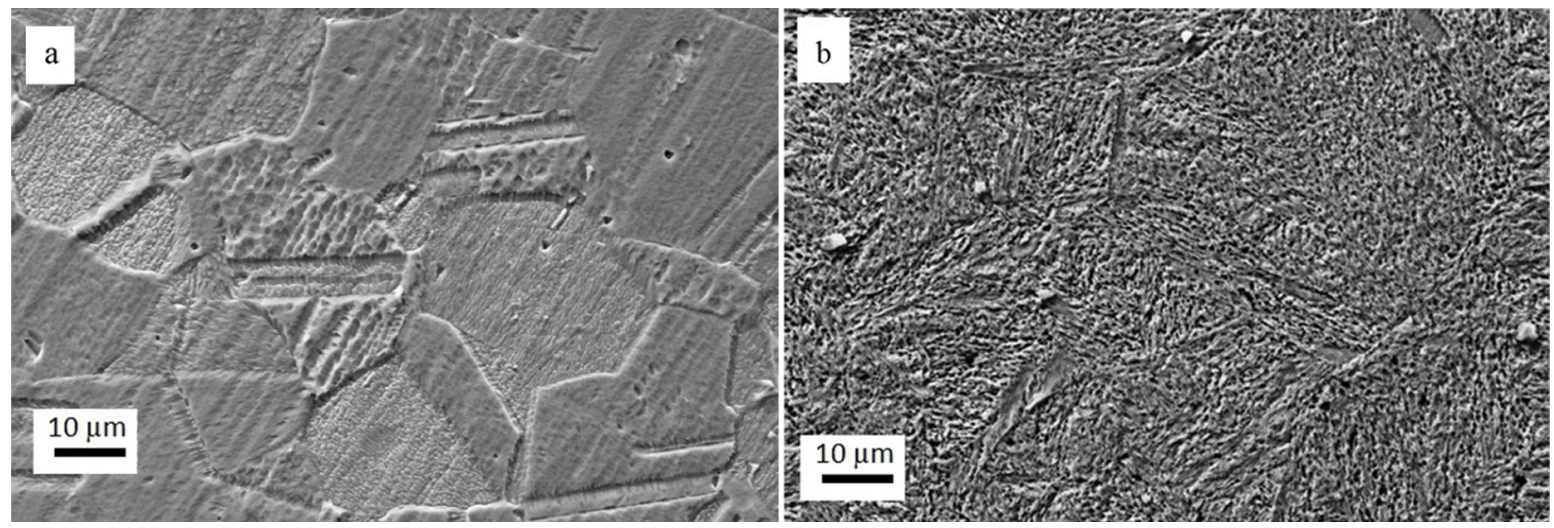

Fig. 1. The base metals microstructures: (a) AISI 316L and (b) AISI 4340.

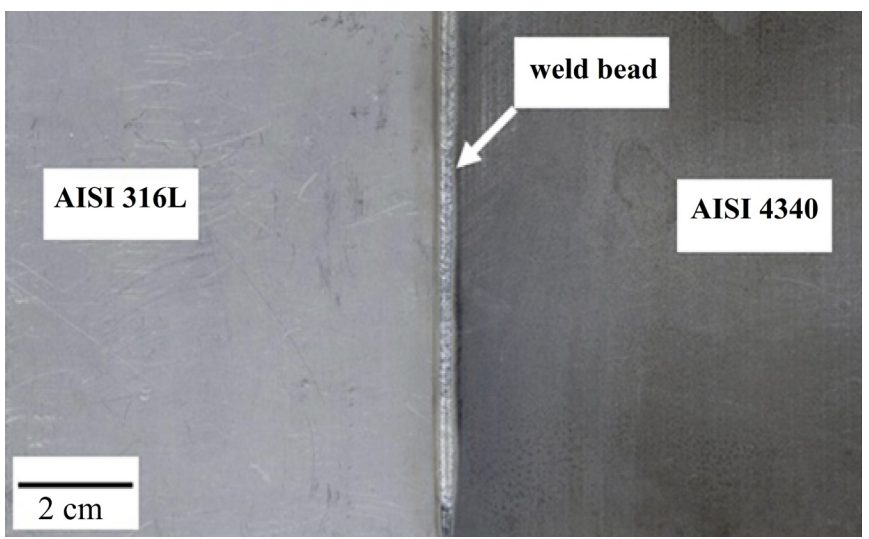

Fig. 2. The sample No. 8 and its joint geometry.

Metallographic examinations of all samples were carried out. Then all the samples were etched using the $45 \mathrm{ml} \mathrm{HCl}, 15 \mathrm{ml} \mathrm{HNO}_{3}$ and $20 \mathrm{ml}$ methanol solution for two minutes. The samples dimensions were measured and examined with optical microscope. The study was focused to investigate the effects of basic and calculated variables on the geometry of the welds and tensile strength. Moreover, the dimensions of the weld can be obtained using the optical microscope. The effects of various variables on the dimensions of the welds are considered by keeping one variable constant. The weld numbers $1-5$ were used to investigate the effects of pulse energy, the tests numbers $6-10$ were used to consider the effects of pulse time and the test numbers 11-15 were used to address the effects of frequency. Moreover, the study was conducted to consider the calculated parameters such as peak power, EPPD (effective peak power density).

To reveal the microstructure and phases, the optical and SEM examinations were carried out. The base metal metallography, fractography and energy-dispersive spectroscopy were conducted on SEM.

The tensile tests were carried out to evaluate the mechanical properties of the fully penetrated samples, and the welding joint tensile specimens were prepared according to ASTM E8 2010 [19]. The strain rates for all samples were set as $2 \mathrm{~mm} / \mathrm{min}$.
The Vickers micro hardness was carried out by applying $100 \mathrm{gr}$ load for $15 \mathrm{~s}$. The micro hardness profiles were obtained in a line across the $316 \mathrm{~L}$ stainless steel, the weld zone and the 4340 steel. The microhardness tests were performed in a line in the position of $0.2 \mathrm{~mm}$ beneath the surface. The indentations were performed at every $0.2 \mathrm{~mm}$ apart from AISI 316L side toward AISI 4340 side.

\section{Results and discussions}

\subsection{The effects of basic variables on the weld geometry}

\subsubsection{The effects of pulse energy on the weld dimensions}

In these test series other basic parameters such as frequency, pulse time, laser beam diameter and welding speed were chosen to be fixed. Pulse energy has a direct effect on the heat input, peak power and average power, according to formula (1)-(3):

$$
\begin{gathered}
P_{\text {average }}=E_{p} \times f \\
P_{\text {peak }}=\frac{E_{p}}{t} \\
\text { heat input }=\frac{P_{\text {average }}}{S}
\end{gathered}
$$

where $f$ is laser frequency $(\mathrm{Hz}), t$ is laser pulse time $(\mathrm{ms})$ and $S$ is welding speed $(\mathrm{mm} / \mathrm{s})$, the average power, peak power and heat input were directly increased with pulse energy. The depth and width of the weld were increased with pulse energy. The width of the weld is more influential to the pulse energy than the depth of the weld (see Fig. 3a). The maximum depth was obtained for the 9.5 and $10.5 \mathrm{~J}$ and a full penetrated weld was obtained with $500 \mu \mathrm{m}$ depths. The maximum width for the $10.5 \mathrm{~J}$ pulse energy was $1715 \mu \mathrm{m}$. However, due to the excess of the weld cross section at the $10.5 \mathrm{~J}$, the optimum pulse energy was obtained as $9.5 \mathrm{~J}$.

\subsubsection{The effects of pulse time on the weld dimensions}

Five of the samples $(6-10)$ were selected to investigate the effect of pulse time on weld geometry. All other parameters such as pulse energy, frequency, laser beam diameter and welding speed were constant. 

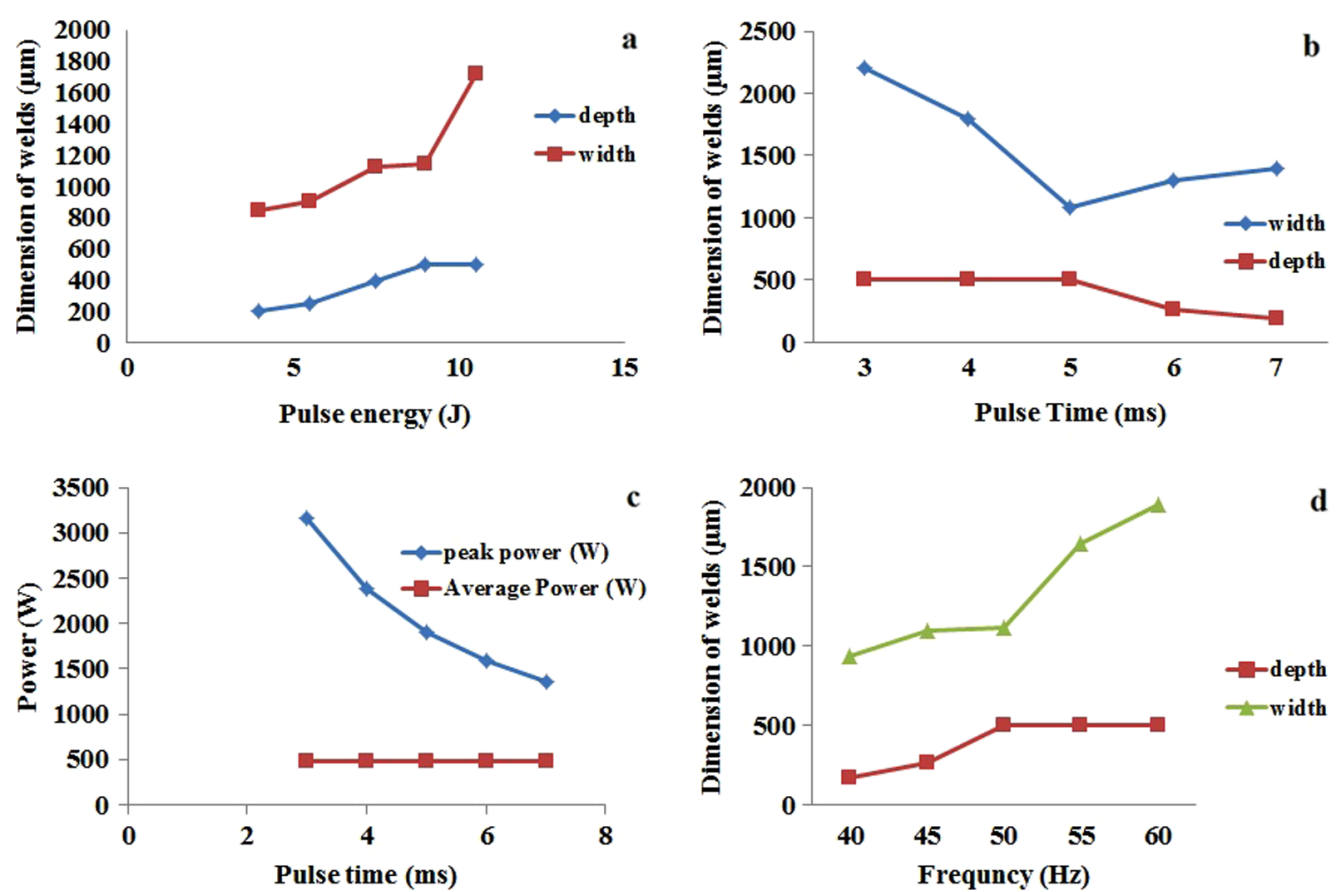

Fig. 3. (a) The effect of pulse energy on weld dimensions, (b) the effect of pulse time on weld dimensions, (c) the effect of pulse time on average and peak power, (d) the effect of frequency on weld dimensions.

Table 3. The results for variation of frequency on other parameters.

\begin{tabular}{lllll}
\hline $\begin{array}{l}\text { Sample } \\
\text { No. }\end{array}$ & $\begin{array}{l}\text { Frequency } \\
(\mathrm{Hz})\end{array}$ & $\begin{array}{l}\text { Average } \\
\text { power } \\
(\mathrm{W})\end{array}$ & $\begin{array}{l}\text { Heat } \\
\text { input } \\
(\mathrm{J} / \mathrm{mm})\end{array}$ & $\begin{array}{l}\text { Overlapping } \\
\text { factor }(\%)\end{array}$ \\
\hline 11 & 40 & 380 & 127 & 92.61 \\
12 & 45 & 428 & 143 & 93.43 \\
13 & 50 & 475 & 158 & 94.09 \\
14 & 55 & 522 & 174 & 94.63 \\
15 & 60 & 570 & 190 & 95.07 \\
\hline
\end{tabular}

Figure 3 b shows that the weld depth and width decrease with pulse time. By increasing the pulse time according to formula (2) peak power was decreased.

According to Figure 3c, pulse time increasing has no effect on the average power but attributed to decreasing of peak power, which was in accordance with formula (2).

The heat input for samples $6-10$ was the same $(158 \mathrm{~J} /$ $\mathrm{mm}$ ) but Figure 3b shows that different peak powers attributed to various depth and width of welds. The results show that peak power has more effect on weld dimensions in comparison with heat input. The optimum value of pulse duration was obtained for the $5 \mathrm{~ms}$ which produced $500 \mu \mathrm{m}$ weld depth and $980 \mu \mathrm{m}$ weld width.

\subsubsection{The effects of frequency on the weld dimensions}

Figure 3d shows that the weld depth and width increases with frequency. The reason can be attributed to the increase of average power and heat input based on formula
(1) and (3). Table 3 shows values of heat input and average power. Moreover, overlapping of pulses were calculated according to formula (4):

$$
O_{f}(\%)=\left\{1-\frac{S}{f(d+S t)}\right\} \times 100
$$

where $f$ is laser frequency $(\mathrm{Hz}), S$ is welding speed $(\mathrm{mm} / \mathrm{s})$, $d$ is laser beam diameter $(\mathrm{mm})$ and $t$ is pulse time (s). The increase of overlapping and density of pulses were due to the weld depth. The maximum value for frequency was obtained for $60 \mathrm{~Hz}$ which produced $500 \mu \mathrm{m}$ weld depth and $1892 \mu \mathrm{m}$ weld width.

According to Table 3 , the overlapping factors in all samples were above $90 \%$ and in this circumstance, pulsed laser welding was similar to continuous welding. Overlapping factor directly affected on average power and heat input. According to Figure 3d increasing the frequencies was more influence on width in comparison with depth of the welds.

\subsection{The effects of calculated variables on the weld geometry}

3.2.1 The effects of peak power on the weld geometry

According to formula (2), increasing the peak power can be achieved by increasing the average power or by decreasing the pulse time. On the other hand, the results show that aspect ratio changes with peak power. According to the results of Figure 4a, the graphs of peak power with average power and peak power with pulse time show an optimum value. The optimum value shows the bilateral, effect of peak power on aspect ratio and weld geometry also it shows optimum peak power with maximum aspect ratio. 

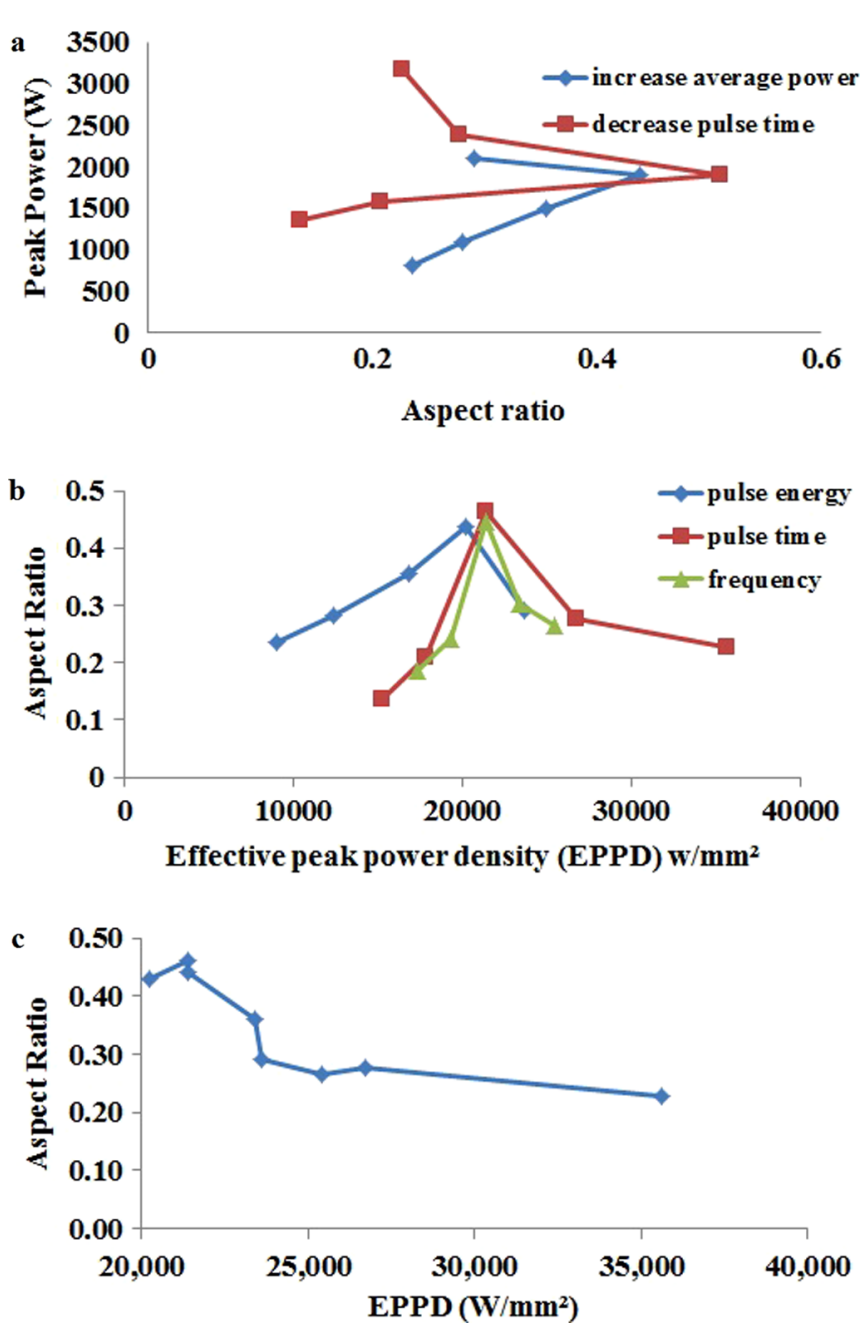

Fig. 4. (a) The effect of peak power on aspect ratio, (b) the effect of EPPD on aspect ratio, (c) the effect of EPPD on aspect ratio in full penetration welds.

Figure 4a shows the reduction of the aspect ratio away from the optimum value. These results were in accordance with investigations carried out by Malek et al. They found that increasing the peak power was attributed to increase of the weld width [13].

Increase of the average power leads to increase of peak power, volume of molten metal and depth of the welds. However, the excessive increasing of average power in sample No. 5 only leads to increase of weld width and decrease of aspect ratio. Therefore, the optimum value of peak power with average power was achieved for sample No. 4 with the magnitude of $1900 \mathrm{~W}$ peak power. On the other hand, decreasing pulse time leads to increase the peak power and aspect ratio. Excessive decreasing pulse time ( 3 and $4 \mathrm{~ms}$ ) leads to instability of welds by creating spatters and increasing width of welds which leads to decrease aspect ratio. Therefore, the optimum value of peak power with pulse time was achieved for sample No. 9 with the magnitude of $1900 \mathrm{~W}$ peak power. Similar results for the other samples show the direct effects of peak power on weld geometry, depth of welds and aspect ratio.

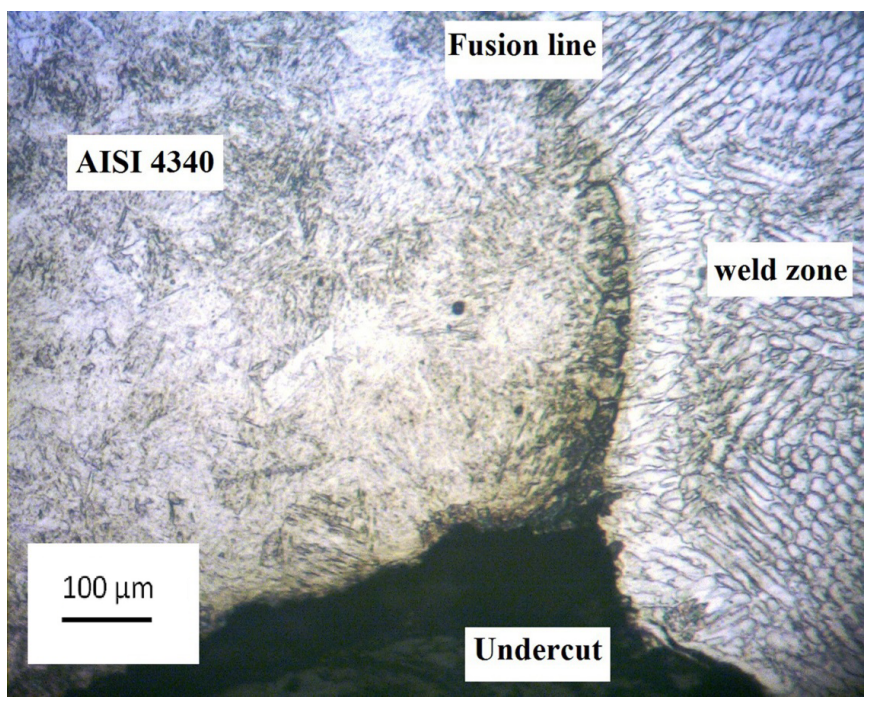

Fig. 5. (a) The undercut on weld number 6 .

3.2.2 The effects of 'Effective Peak Power Density' on the weld geometry

A complete investigation on laser parameters aiming for the optimum weld configuration requires consideration of calculated parameters besides basic parameters. Calculated parameters could reveal how the pulsed laser and overlapping factor act on the weld geometry. One of the calculated parameters was introduced as "Effective Peak Power Density" calculated by using formula (5) according to:

$$
\mathrm{EPPD}=\text { peak power } \times \frac{F}{\text { area of spot on work piece }}
$$

where " $F$ " is the cumulative overlapping index as defined in Malek et al. (2001). This index can be calculated as

$$
\begin{gathered}
F=1+n\left\{1-\frac{(n+1) S}{2 f d}\right\} \\
n=\frac{d f}{S}
\end{gathered}
$$

where $S$ is the welding speed $(\mathrm{mm} / \mathrm{s}), f$ is frequency $(\mathrm{Hz}), d$ is beam diameter $(\mathrm{mm})$ and $\mathrm{n}$ is the number of overlapping pulses on area of one pulse. The "effective peak power density" is the concentration of the power at the part, and is determined by dividing the peak power by the focus spot size area. Table 4 shows the results of calculation item such as $n, F$ and EPPD.

The EPPD values have important effect on weld size and geometry. According to Table 4, the EPPD less than $20000 \mathrm{~W} / \mathrm{mm}^{2}$ lead to partial penetrated welds and to achieve full penetrated weld should be increasing up to $20000 \mathrm{~W} / \mathrm{mm}^{2}$. The changes of EPPD for three specimens series were studied in Figure 4b. The results show that each series has the given optimum point with maximum aspect ratio. The moving from optimum point has lead to decrease aspect ratio. Actually the closing to optimum point on EPPD graph could be considered the base for optimized 
Table 4. The results for calculations of EPPD.

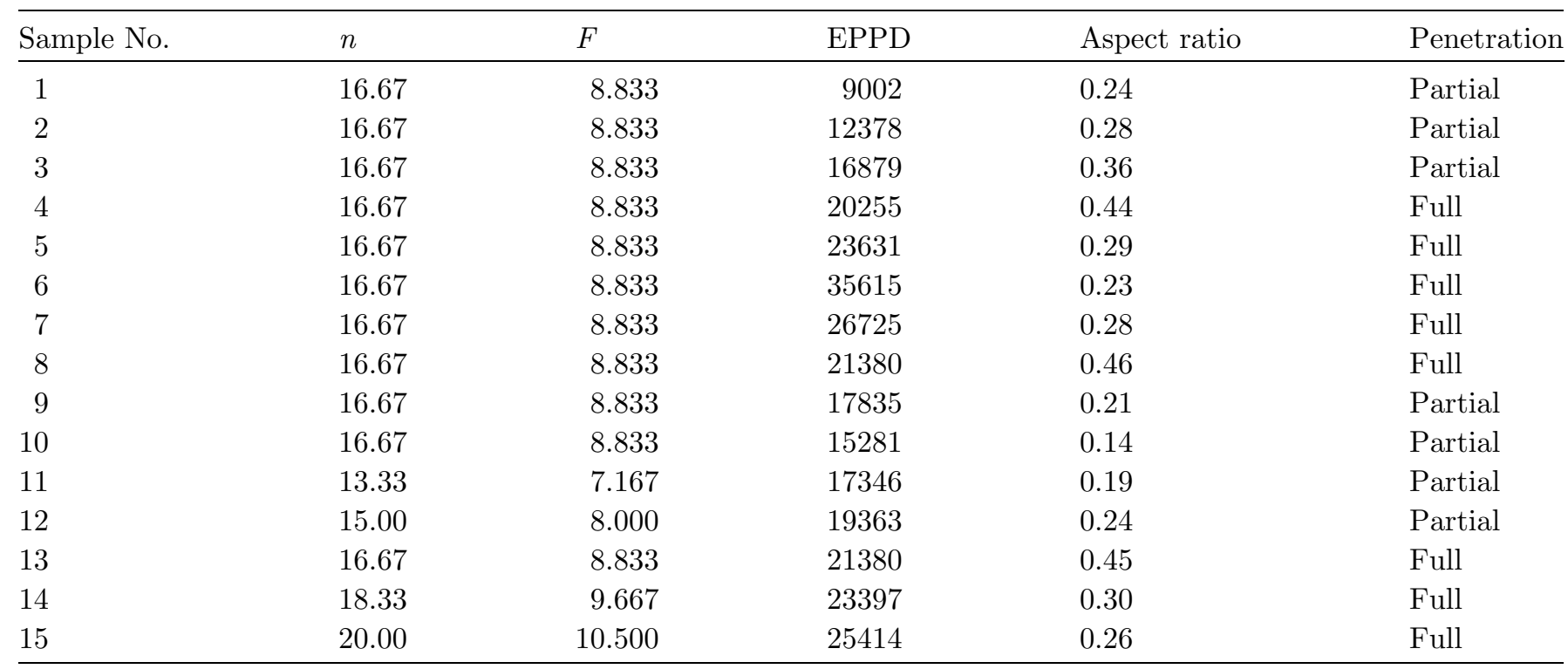

Table 5. The results of tensile test from base metals and full penetrate welds.

\begin{tabular}{lllll}
\hline Sample number & Yield stress $(\mathrm{MPa})$ & Ultimate stress $(\mathrm{MPa})$ & Location of failure & Heat input $(\mathrm{J} / \mathrm{mm})$ \\
\hline AISI 4340 base metal & 475 & 744 & - & - \\
AISI 316L base metal & 190 & 515 & - & - \\
4 & 210 & 543 & AISI 316L & 150 \\
5 & 221 & 568 & weld/HAZ 316L & 192 \\
6 & 178 & 198 & weld & 158 \\
7 & 182 & 224 & weld & 158 \\
8 & 235 & 590 & AISI 316L & 158 \\
13 & 211 & 540 & AISI 316L 316L & 158 \\
14 & 225 & 580 & weld/HAZ 316L & 190 \\
15 & 198 & 524 & & 174 \\
\hline
\end{tabular}

parameters selection. The optimum point for pulse energy, pulse time and frequency was 20255,21380 and $21380 \mathrm{~W} /$ $\mathrm{mm}^{2}$ respectively.

Moreover, Figure 4c shows the relation between EPPD and aspect ratio for full penetration welds. The optimum points have maximum aspect ratio and moving from these points lead to excessive EPPD and decrease the aspect ratio. This means increasing the welds width without any benefit.

\subsection{The effect of laser parameters on tensile test measurements}

According to Table 5, the tensile tests carried out for full penetrate specimens. The results show that all specimens were failed at 500-550 MPa except two specimens (number 6 and 7). The results of tensile test from base metal according to Table 5 show that the results of successful tensile tests according to Table 5 were a little above AISI $316 \mathrm{~L}$ base metal.
The reason of low tensile strength for samples No. 6 and 7 can be described; the pulse times of specimen numbers 6 and 7 were too low and magnitude of peak power is high according to Figure 3c so that the defects of weld such as undercut were seen as shown in Figure 5. The reason for failure is the stress concentration occurred as the weld defect leads to fail these specimens in the low stress range. Moreover, Figure 7 shows the excessive EPPD values for samples 6 and 7 .

According to Figure 6, the location of failures for samples No. 4, 8, 13 and 14 were the AISI 316L base metal because this part of joints has lower strength than the weld metal and the AISI 4340 base metal. The failures shape shows ductile failure with 45-degree angle of shear. The location of failures for samples No. 5 and 15 was the heat affected zone (HAZ) close to fusion line in AISI 316L side (see Fig. 6). According to Table 1, the maximum heat input for these samples according to Tables 1 and 5 was 190 and $192 \mathrm{~J} / \mathrm{mm}$ respectively. This attribute means high heat input that leads to create welds with high width and low 


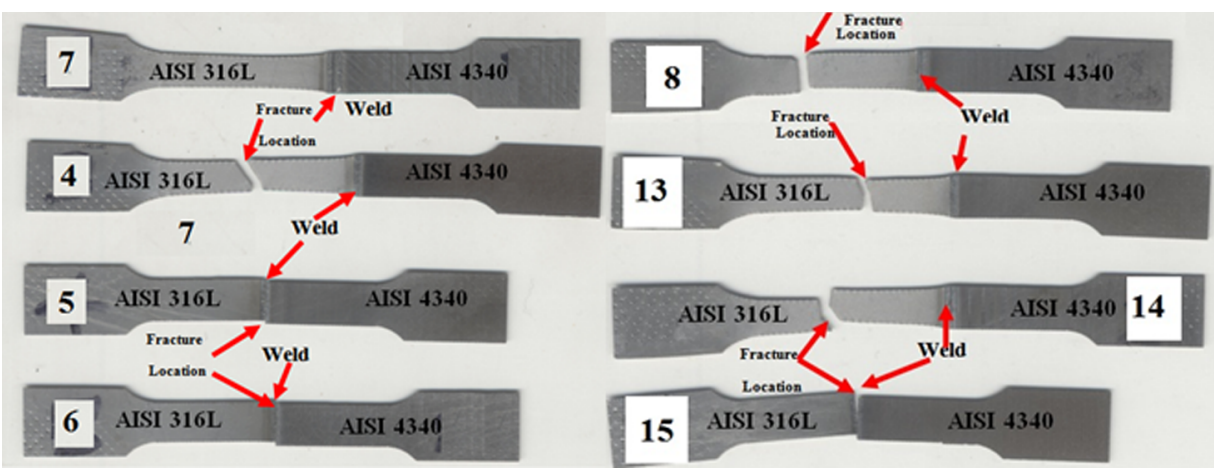

Fig. 6. The location of failures on tensile test specimens.

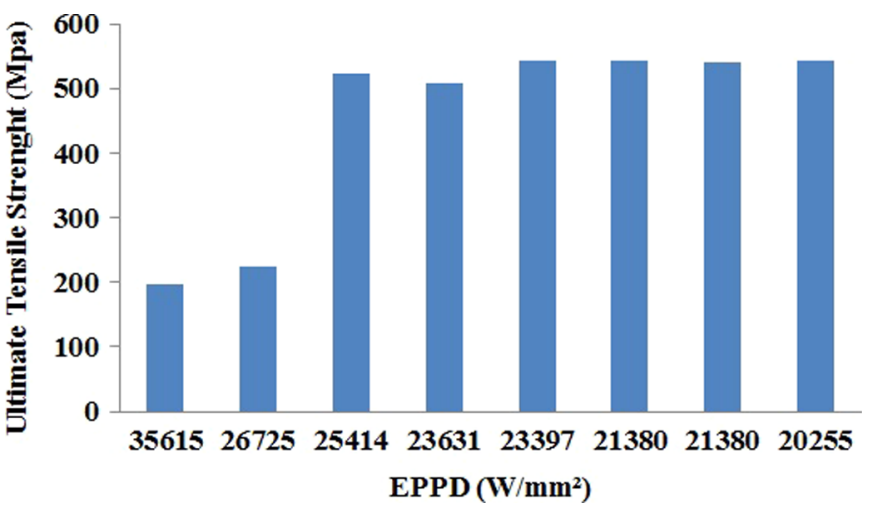

Fig. 7. The effect of EPPD on ultimate tensile stress of full penetrated welds.

aspect ratio. Moreover, this attributes to create wide HAZ and failures were done from this zone. Moreover, the brittle fracture surface, according to Sufizadeh et al. [20], could be attributed to the high induced heat input and, therefore, increase of Chromium content and presence of chromium rich phases in HAZ of AISI 316L side.

The dimples in the SEM photomicrograph of the fractured cross section shown in Figure 8 verify the ductile fracture behavior of the sample No. 8 with fracture on AISI $316 \mathrm{~L}$ base metal.

\section{The effects of laser parameters on weld microstructure}

Based on Figure 9, austenitic and fine grains are seen as the dissimilar weld microstructure. The laser weld parameters play important role on weld microstructure and mechanical properties due to their effect on heat input and power density. The effects of pulse energy, pulse time and frequency on weld grain size were also investigated.

Figure 10a shows that the weld grain size increases with pulse energy and frequency. The reason can be attributed to the increase of average power and heat input based on formula (1) and (3) which reduces the cooling rate. Therefore, there is enough time for excessive grain growth in the weldment solidification period. Moreover, the observation showed that increasing the heat input

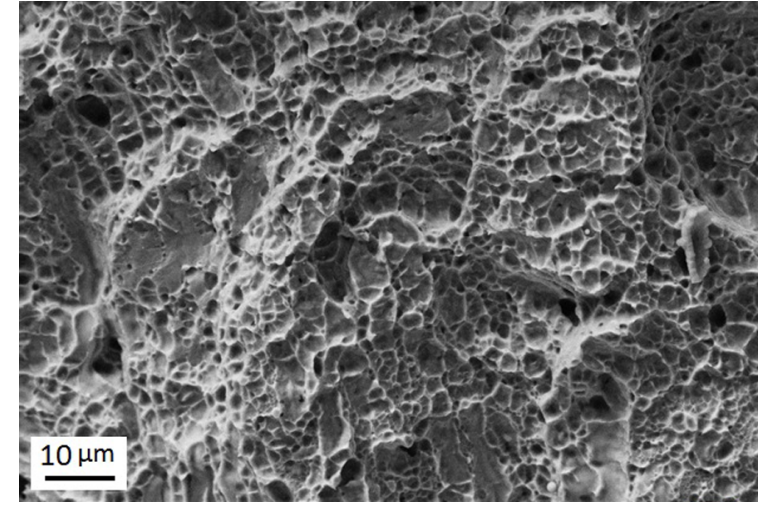

Fig. 8. The SEM photomicrograph of the fractured cross section for sample No. 8.

values more than $150 \mathrm{~J} / \mathrm{mm}$ will led to significant grain growth rate but in lower heat input values the gradual growth will accrued. The reason can be attributed to the excessive increase of heat input (more than sample 4 and 13 that have full penetration). This only led to increase in weld volume and decrease in cooling rate. At this condition there is much more time for growth stage during solidification.

The heat input values for welding of the samples No. 5 and 15 are 190 and $192 \mathrm{~J} / \mathrm{mm}$ respectively but the grain size measurements show different values according to Figure 11a as well as microstructures in Figure 9. The grain sizes for samples No. 5 and 15 were 12 and $21 \mu \mathrm{m}$ respectively. This means that increasing frequency plays significant role in grain size in comparison with pulse energy in similar heat input values. The reason can be attributed to the high frequency which increases the number of laser pulses in fixed time and each pulse faced on and each pulse faced on next pulse face before cooling repeats. This sequence can lead to appropriate situation for grain growth.

The effects of pulse time (sample No. 6-10) on weld grain size were investigated. Increasing pulse time led to increase of peak temperature and grain growth during solidification. On the other hand the increase of pulse time led to decrease peak power according to Table 5. These antonym elements according to Figure 10b led to reduce the effect of pulse time on weld grain size. 


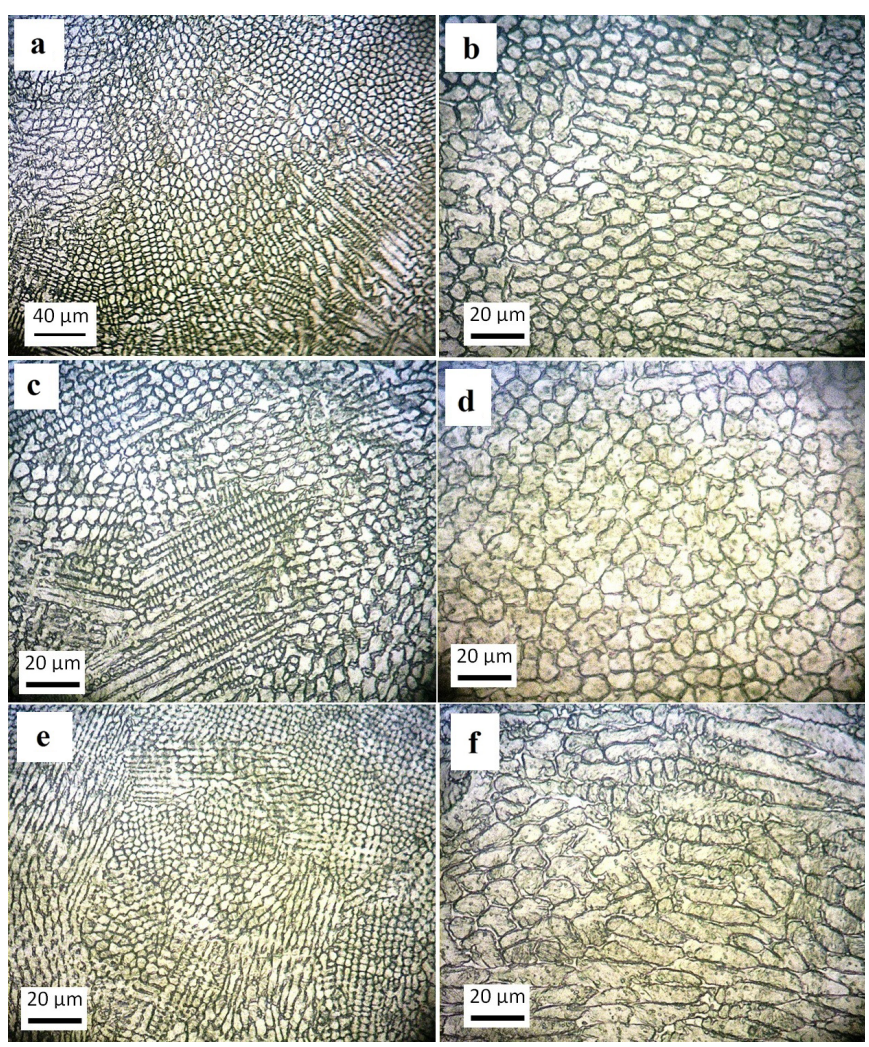

Fig. 9. The austenitic weld microstructures (a) sample No. 2, (b) sample No. 5, (c) sample No. 7, (d) sample No. 10, (e) sample No. 11, (f) sample No. 15.

\section{The effects of laser parameters on heat affected zone}

According to Figure 11a, the increasing heat input in pulse energy (specimen No. 1 to 5) and frequency (specimen No. 11 to 15) series leads to increase heat affected zone (HAZ) width in both sides. These results were confirmed by micrographs shown in Figures 12 and 13. The increasing heat input is attributed to wide region in base metal which is exposed to high temperature and microstructure changes were accrued. Moreover, these changes in full penetration samples are changing faster because in conduction mode (in the low power laser machine) the aspect ratio (weld depth/ base metal thickness) plays important role in heat sink and cooling rate. In partial penetration welds, the effect of base metal heat sink (due to more base metal thickness values than weldment) increases and the base metal close to fusion line is exposed to high temperature in much shorter period of time and then the HAZ width will reduced. In the full penetration samples, the similar thickness for base metals and welds lead to reduce effect of base metal heat sink, increase of heating time in HAZ and consequently, increase of HAZ width.

According to Figures 11a, 12 and 13 the HAZ widths changed in the two sides of each specimen due to using different materials with different heat conductivity coefficients based on Figure 11a, the HAZ width in AISI 316L stainless steel side was 3 or 4 times greater than that
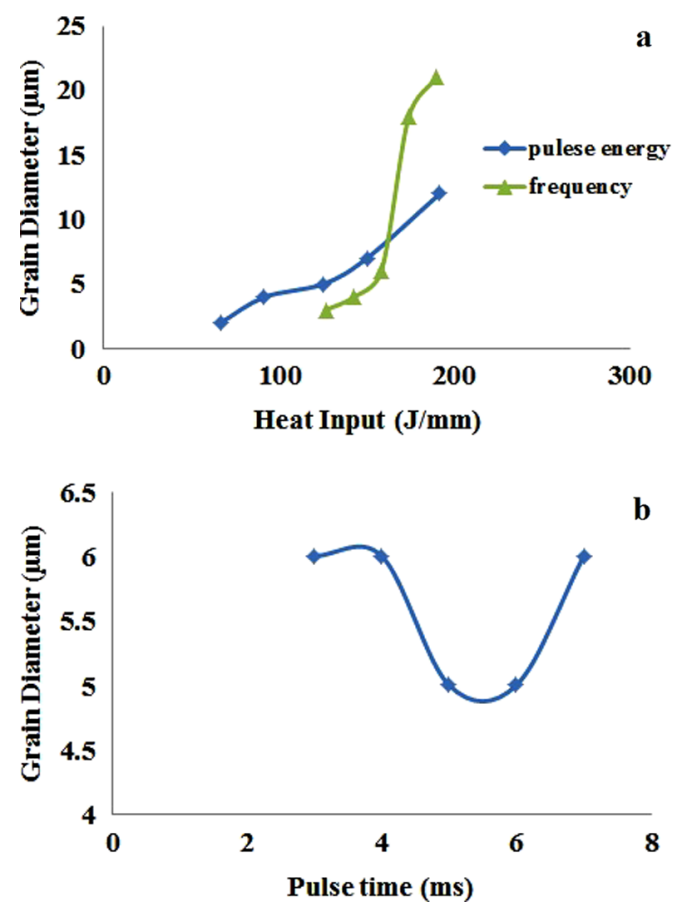

Fig. 10. (a) The effects of pulse energy and frequency on weld microstructure grain size, (b) the effect of pulse time on weld microstructure grain size.

of AISI 4340 steel side. The major reason is attributed to the different heat conductivity coefficients of AISI 316L stainless steel and AISI 4340 steel. The heat conductivity coefficients were 44.5 and $16.3 \mathrm{~W} / \mathrm{m} \cdot \mathrm{K}$ for AISI 4340 steel and AISI 316L stainless steel, respectively. In fact, the heat conductivity coefficient of AISI 4340 is approximately 3 times greater than that of AISI 316L stainless steel. Therefore, the heat input induced in the materials leads to produce smaller HAZ size in the AISI 4340 steel side than the HAZ size in the AISI 316L stainless steel side.

The effects of pulse time on HAZ width were investigated by changes of HAZ width with peak power. The results of Figure 11b show the very low variation of HAZ width in comparison with Figure 11a. In fact the similar heat inputs for this series show that the heat input has an important factor for HAZ width. Moreover the minimum HAZ width in this series was accrued for sample No. 8 which according to Figure $4 a$ has the maximum aspect ratio (weld depth/width). The sample No. 8, based on Figure $4 \mathrm{~b}$ and c, has an optimum EPPD and focused heat which can lead to decrease the width of weld and HAZ in comparison with other samples in this series with similar heat inputs.

\section{The effect of laser parameters on micro hardness measurements}

Figure 14 shows the micro hardness test results for each welding series based on Table 1 . In over view, all series have similar characteristics and the hardnesses of welds were measured in a line along with both base metals. These results were confirmed by austenitic microstructure introduced in 

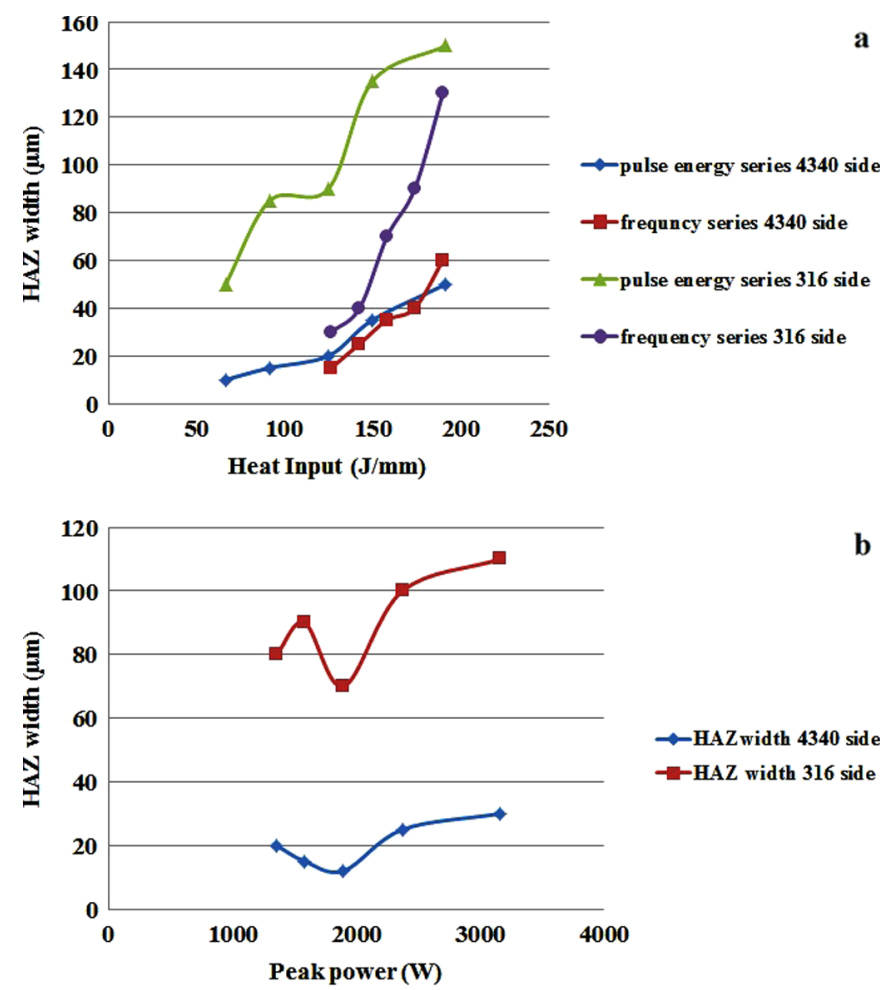

b

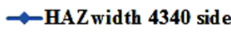
$\rightarrow-H A Z$ width 316 side

Fig. 11. (a) The effect of heat input variations due to pulse energy and frequency variations on HAZ width, (b) the effect of peak power variations on HAZ width.

Figure 9. The higher hardness on weld metals is due to fine grain microstructure in comparison with base metal. Moreover, the austenite microstructures were softener than martensitic microstructure in AISI 4340 base metal.

Figure 14a shows the hardness test results for energy pulse variation series, the increase of pulse energy led to slight decrease of hardness. These results were attributed to increase of heat input and decrease of cooling rate which are in good agreement with metallography results shown in Figure 9. The maximum hardness was measured on sample No. 1 which has the minimum heat input $(67 \mathrm{~J} / \mathrm{mm})$ and the average weld grain size of $2 \mu \mathrm{m}$. The minimum hardness was measured on sample No. 5 which has the maximum heat input $(192 \mathrm{~J} / \mathrm{mm})$ and the average weld grain size of $12 \mu \mathrm{m}$.

Figure 14b shows the uniform characteristics for hardness results in pulse time variation series. In fact, these results are in accordance with metallography results about insensitive grain size changes with pulse time. The steady heat input and subsequently welds grain size led to less change on hardness results. In these samples the hardness values are in the range of $470-560 \mathrm{HV}$ which are in accordance with fine grain austenitic microstructure $(4-6 \mu \mathrm{m})$.

Figure 14c shows the hardness test results for frequency variation series. The increase of frequency led to decrease of hardness. These results were attributed to increase of heat input and decrease of cooling rate which are in good agreement with metallography results shown in Figure 9. The amount of hardness reduction for sample No. 15 with the frequency of $60 \mathrm{~Hz}$ was measured about $50-80 \mathrm{HV}$, in comparison with sample No. 11 with the frequency of $40 \mathrm{~Hz}$.

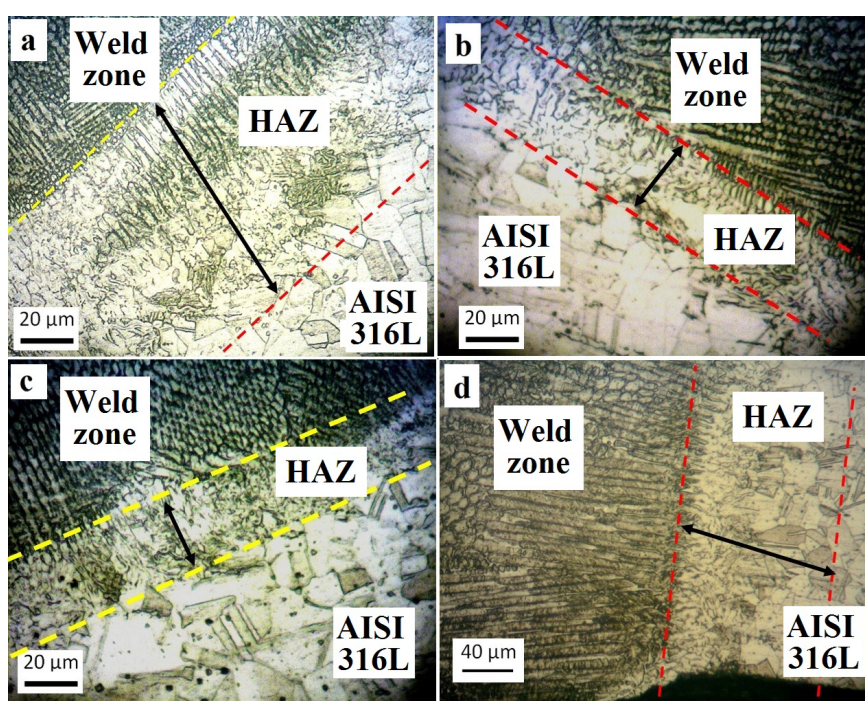

Fig. 12. The microstructure of HAZ on AISI $316 \mathrm{~L}$ side (a) sample No. 9, (b) sample No. 11, (c) sample No. 12, (d) sample No. 15.

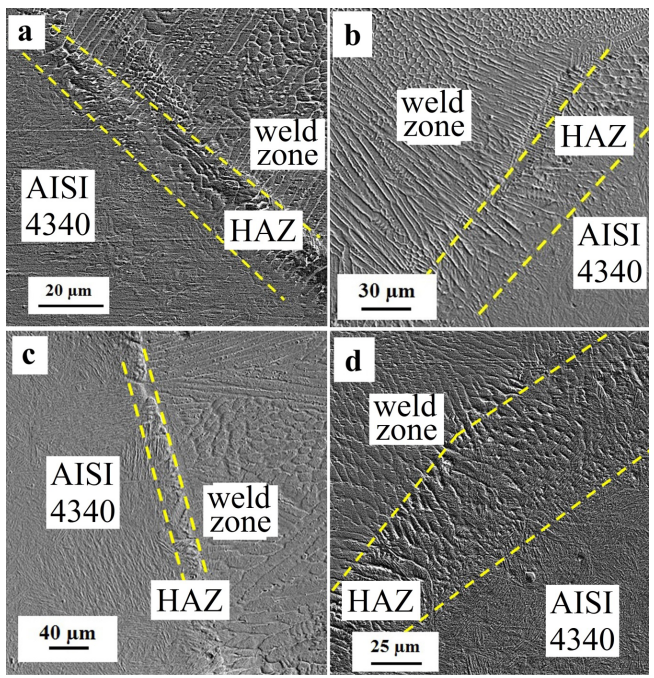

Fig. 13. The microstructure of HAZ on AISI 4340 side (a) sample No. 3, (b) sample No. 5, (c) sample No. 13, (d) sample No. 15.

\section{Conclusions}

In this study, the effects of laser parameters on the weld dimensions and mechanical properties were considered and the following conclusions can be drawn from this investigation:

- The weld depth and width increased with pulse energy and frequency and the weld depth and width decrease with pulse time;

- The effective peak power density (EPPD) had important role to achieve the sound weld with minimum heat input and full penetration. In the full penetration samples, increasing the optimum EPPD led to increase the aspect ratio;

- The tensile tests results showed that all sound full penetration specimens were failed at AISI $316 \mathrm{~L}$ base metal or HAZ in this side so the results were acceptable; 

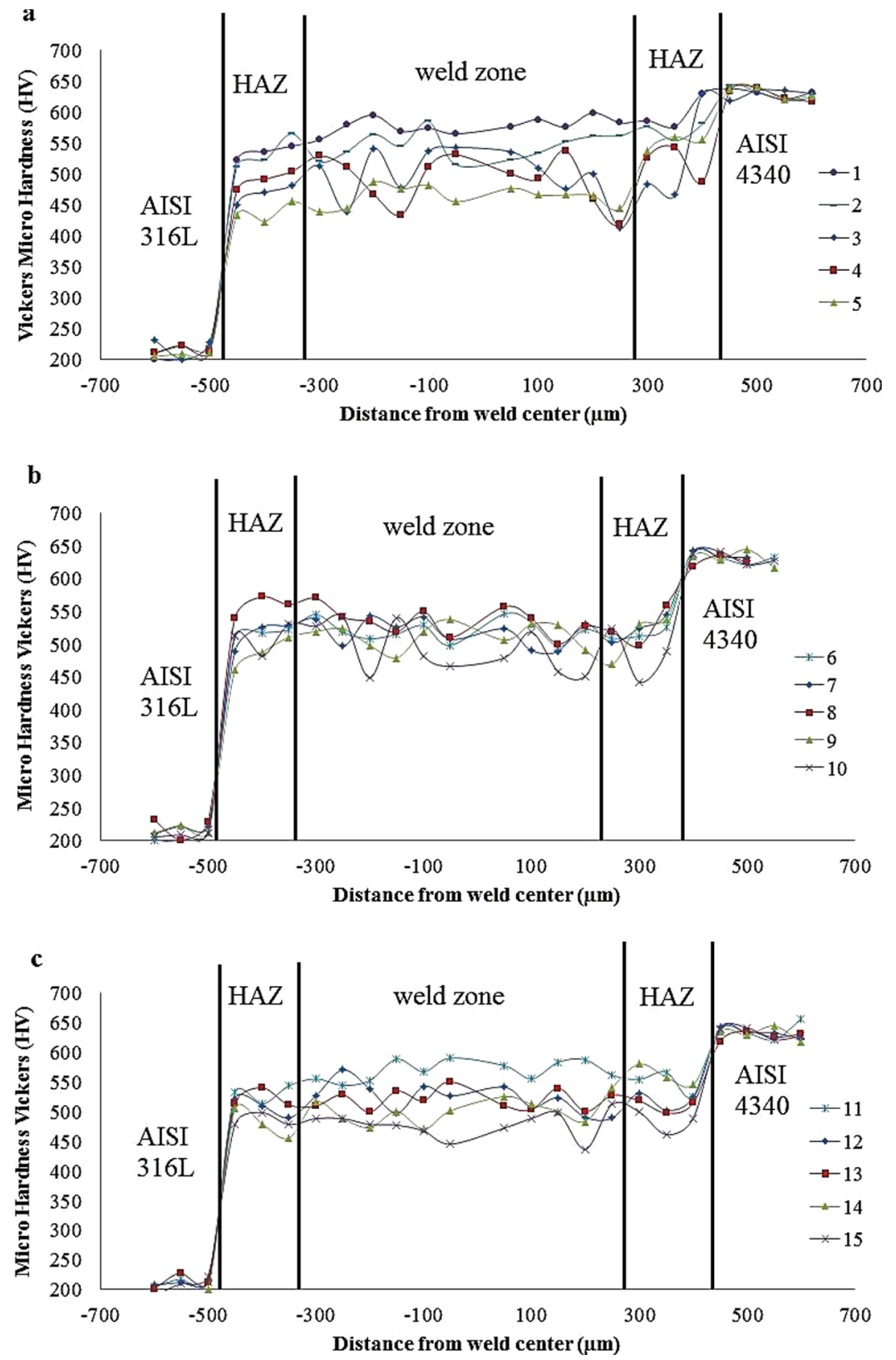

Fig. 14. The Vickers micro hardness test results (a) pulse energy variation series (samples Nos. 1-5), (b) pulse time variation series (samples Nos. 6-10), (c) frequency variation series (samples Nos. 11-15).

- The results showed that the HAZ width is changed from one side to another side of each specimen due to the different heat conductivity coefficients of the base metals. Because of smaller heat conductivity coefficient of AISI 316L stainless steel, the HAZ width in the AISI 316L stainless steel side was 3 or 4 times greater than that of in the AISI 4340 side. Moreover, the increasing of heat input lead to increase HAZ width in both sides;

- The weld grain size increases with pulse energy and frequency;

- The optimum weld was achieved for sample number 8 (pulse energy $9.5 \mathrm{~J}$, frequency $50 \mathrm{~Hz}$, pulse time $5 \mathrm{~ms}$, average power $475 \mathrm{~W}$ and heat input $158 \mathrm{~J} / \mathrm{mm}$ ) with minimum cross section area, maximum aspect ratio (0.46), EPPD $\left(21380 \mathrm{~W} / \mathrm{mm}^{2}\right)$, low range heat input $(158 \mathrm{~J} / \mathrm{mm})$ and good tensile strength.

\section{Nomenclature}

$d \quad$ Laser beam diameter, $\mathrm{mm}$

$E_{p} \quad$ Pulse energy, J

EPPD Effective peak power density, $\mathrm{W} / \mathrm{mm}^{2}$

$f \quad$ Frequency, $\mathrm{Hz}$

$F \quad$ Cumulative overlapping index

$O_{f} \quad$ Overlapping factor

$P_{\text {average }}$ Average power, $\mathrm{W}$ 
$P_{\text {peak }} \quad$ Peak power, $\mathrm{W}$

$S \quad$ Welding speed, $\mathrm{mm} \mathrm{s}^{-1}$

$t \quad$ Pulse time, ms

Acknowledgment. The authors would like to thank the school of metallurgy and materials engineering of the University of Tehran for providing the authors their SEM and EDS equipment's and Payesh Gostaran Pishro Co for providing any cost of this project.

\section{References}

[1] S. Kondapalli, C. Srinivasa, D. Rao, A review on welding of AISI 304L austenitic stainless steel, J. Manuf. Sci. Prod. 14 (2014) 1-11

[2] B. Shanmugarajan, P. Sathiya, G. Buvanashekara, Mechanical and metallurgical properties of autogenous laser welded P92 material, J. Manuf. Process. 24 (2016) 11-18

[3] M. Nascimento, R. Souza, W. Pigatin, H. Voorwald, Effects of surface treatments on the fatigue strength of AISI 4340 aeronautical steel, Int. J. Fatigue 23 (2001) 607-618

[4] A. Ventrella, J. Berretta, W. Rossi, Pulsed Nd:YAG laser seam welding of AISI 316L stainless steel thin foils, J. Mater. Process. Tech. 210 (2010) 1838-1843

[5] S. Katayama, Laser welding of aluminum alloys and dissimilar metals, Weld Int. 18 (2004) 618-625

[6] J. Yang, Y. Li, H. Zhang, Microstructure and mechanical properties of pulsed laser welded $\mathrm{Al} /$ steel dissimilar joint, Trans. Nonferrous Met. Soc. China 26 (2016) 994-1002

[7] W. Duley, Laser welding, Wiley-Interscience publication, New Jersey, 1998

[8] M.J. Torkamany, J. Sabbaghzadeh, M.J. Hamedi, Effect of laser welding mode on the microstructure and mechanical performance of dissimilar laser spot welds between low carbon and austenitic stainless steels, Mater. Des. 34 (2012) 666-672

[9] M.M.A. Khan, L. Romoli, M. Fiaschi, G. Dini, F. Sarri, Laser beam welding of dissimilar stainless steels in a fillet joint configuration, J. Mater. Process. Tech. 212 (2012) 856-867
[10] A.P. Tadamalle, Y.P. Reddy, E. Ramjee, Influence of laser welding process parameters on weld pool geometry and duty cycle, Adv. Prod. Eng. Manag. 8 (2013) 52-60

[11] S. Karami, H. Jafarian, A. Eivani, S. Kheirandish, Engineering tensile properties by controlling welding parameters and microstructure in a mild steel processed by friction stir welding, Mater. Sci. Eng. A 670 (2016) 68-74

[12] S. Ugender, A. Kumar, A. Reddy, Experimental investigation of tool geometry on mechanical properties of friction stir welding of AA 2014 aluminium alloy, Procedia Mater. Sci. 5 (2014) 824-831

[13] F. MalekGhaini, M.J. Hamedi, M.J. Torkamany, J. Sabbaghzadeh, Weld metal microstructural characteristics in pulsed Nd:YAG laser welding, Scr. Mater. 56 (2007) 955-958

[14] S.A.A. Akbari Mousavi, A.R. Sufizadeh, Metallurgical investigations of pulsed Nd:YAG laser welding of AISI 321 and AISI 630 stainless steels, Mater. Des. 30 (2009) 3150-3157

[15] A. Yonezu, H. Akimoto, S. Fujisawa, X. Chen, Spherical indentation method for measuring local mechanical properties of welded stainless steel at high temperature, Mater. Des. 52 (2013) 812-820

[16] C. Lipoid, J. Kotecki, Welding metallurgy and weldability of stainless steels, John Wiley and Sons, New York, 2005

[17] S. Kumar, N. Murugan, K.K. Ramachandran, Influence of tool material on mechanical and microstructural properties of friction stir welded $316 \mathrm{~L}$ austenitic stainless steel butt joints, Int. J. Refract. Met. Hard Mater. 58 (2016) 196-205

[18] A. Hasc, E. Unal, Fatigue behavior of AISI 304 steel to AISI 4340 Steel welded by friction welding, J. Mater. Sci. 41 (2006) 3233-3239

[19] Standard Test Techniques for Tension Testing of Metallic Materials, ASTM E8/E8M-08, West Conshohocken, USA, 2010

[20] A.R. Sufizadeh, S.A.A. Akbari Mousavi, Microstructures and mechanical properties of dissimilar Nd:YAG laser welding of AISI4340 and AISI316L steels, Int. J. Miner. Met. Mater. (2017), DOI: 10.1007/s12613-017-1435-0 